\title{
Assessment and Standardization of Microwave and Sodium Benzoate Treatments for Controlling Fermentation of Cauliflower Pickle
}

\author{
Jeelani Raja*, Sirfaraz Hussain Dar and F.A. Masoodi \\ Department of Food Science and Technology, University of Kashmir, Hazratbal, Srinagar-190006, J\&K, India \\ *Corresponding author: jeelaniraja@uok.edu.in
}

Received: $11-08-2020$

Revised: $24-10-2020$

Accepted: 29-11-2020

\begin{abstract}
To control the over-acidification of fermented products has remained a challenging task for technologist and food processors. Standardization and optimal use of sodium benzoate and microwave treatment was carried out to control the fermentation of cauliflower pickle. The samples containing sodium benzoate at different concentrations $\mathrm{S}_{1}(350 \mathrm{ppm}), \mathrm{S}_{2}$ (450 ppm) and $S_{3}(550 \mathrm{ppm})$ and the samples treated with microwave heat $\mathrm{M}_{1}(2.5 \mathrm{~min}), \mathrm{M}_{2}(3.5 \mathrm{~min})$ and $\mathrm{M}_{3}(4.5 \mathrm{~min})$ for different time periods were compared with the control $(\mathrm{C})$. The $\mathrm{pH}$, titratable acidity (TA), texture and bacterial counts were periodically analyzed. The results showed that samples $\mathrm{M}_{2}$ and $\mathrm{M}_{3}$ showed significantly lower titratable acidity of 0.99 and 0.86 , respectively and higher $\mathrm{pH} 4.76$ and 4.33, respectively than the control (TA-1.45; pH- 3.70) throughout the 4 weeks of fermentation. Sample $\mathrm{M}_{1}$ showed better results for $\mathrm{pH}(4.84)$, acidity (0.96), texture (6.6) and overall acceptability (8.1) than other treated samples. Samples $S_{1}, S_{2}$ and $S_{3}$ showed no significant difference to that of control. These results indicate that microwave treatment was able to arrest/slowdown fermentation of the pickle by inhibiting the growth of lactic acid bacteria (LABs), there by controlling the acid production.
\end{abstract}

Keywords: Fermentation, Microwave, Pickle, Sodium benzoate.

Due to diverse nutrient profile, vegetables are an important component of human diet. Not only that they are rich in phyto-chemicals and have been considered as important chemical reagents (Cordell et al. 2007) which improve human nutrition and health by various bioactivities. They represent a rich source of nutrients like carbohydrates, proteins, vitamins, minerals and fiber and non-nutrient phytochemicals such as sulfur containing chemicals that contribute to normal functioning of human body (Wettasinghe et al. 2002). These bioactive phytochemicals can modulate synthesis and absorption of cholesterol; reduce platelet aggregation and blood pressure. It has been reported that high consumption of vegetables significantly reduced the risk of cancer in humans (Block et al. 1992). Vegetables are also rich in antioxidants and consumption of these antioxidant-rich foods may improve antioxidant defense mechanism. Cauliflower (Brassica oleraceae) is one of the vegetables in the family Brassicaceae. It is low in fat and carbohydrates but high in dietary fiber, folate, water and vitamin C, possessing a high nutrient density. Cauliflower contains $4.97 \mathrm{~g}$ carbohydrates, $1.9 \mathrm{~g}$ sugars, $1.92 \mathrm{~g}$ protein, $0.28 \mathrm{~g}$ total

How to cite this article: Raja, J., Dar, S.H. and Masoodi, F.A. (2020). Assessment and Standardization of Microwave and Sodium Benzoate Treatments for Controlling Fermentation of Cauliflower Pickle. Intl. J. Ferment. Food, 9(2): 43-50. 
fat, $0 \mathrm{mg}$ cholesterol, $2 \mathrm{~g}$ dietary fiber and an energy value of $25 \mathrm{kcal}$. Fresh cauliflower is a rich source of vitamin $\mathrm{C}$. It also contains good amount of B-complex vitamins like pantothenic acid $(0.667 \mathrm{mg})$, folate $(57 \mu \mathrm{g})$, pyridoxine $(0.184 \mathrm{mg})$, thiamine $(0.050 \mathrm{mg})$, niacin $(0.507 \mathrm{mg})$ and vitamin $\mathrm{K}(15.5 \mu \mathrm{g})$ (USDA, 2009). Cauliflower contains several phytochemicals like kaempferol $\left(\mathrm{C}_{15} \mathrm{H}_{10} \mathrm{O}_{6}\right)$, quercetin $\left(\mathrm{C}_{21} \mathrm{H}_{20} \mathrm{O}_{12}\right)$ and a flavonoid isorhamnetol $\left(\mathrm{C}_{16} \mathrm{H}_{12} \mathrm{O}_{7}\right)$ which are common in the cabbage family that may be beneficial to human health (Vasanthi et al. 2009). Various studies regarding health benefits of cauliflower have demonstrated that they possess anti-proliferative activity (Dominique et al. 2009). Cauliflower heads contain several health benefiting phyto-nutrients such as indole-3-carbinol, 3, 3-di indolylmethane, sulphorane etc. that prevent overweight, diabetes and offer protection from prostrate cancers. Cauliflower contains in particular flavonoids and glucosinolates, which have been intensively researched for their health benefits (Hertog et al. 1995; Shivapriya et al. 2012). Cauliflower contains some enzymes which may interfere with thyroid hormone formation especially in people with iodine deficiency and hence can be goitrogenic (Rao 1995).

The vegetables once harvested are very much prone to spoilage due to their perishable nature. In order to make continuous supply of the nutritious and phytochemicals rich vegetables a need is felt to prevent them from immediate spoilage. Various processing methods have been applied to preserve and enhance the storage life of these vegetables. Fermentation has been considered as most viable processing method to make the vegetables preserved for consumption in off periods. Fermentation has been described as an energy yielding metabolism in which microbes incompletely oxidize the organic substrates which act as electron acceptors (Adams and Nout, 2001). Fermentation has been used as a method of preservation of perishable raw materials since Neolithic period (around 10000 years BC) (Prajapati and Nair, 2003). Fermentation inhibits the growth of pathogens and as such improves food safety (Adams and Mitchell, 2002). Fermentation not only preserves the food but also improves its nutrient content and their bioavailability due to the breakdown of antinutritional factors (Van Boekel et al. 2010; Sicard and Legras, 2011). Vegetables possess appreciable quantity of fermentable sugars, organic acids and amino acids for the growth and metabolism of LAB (Li, 2004) which significantly affects the flavour and sensory characteristics of vegetables. Since vegetables naturally harbor various LABs therefore as soon as they get the favorable conditions of salt concentration, anaerobic condition, water activity and temperature they undergo lactic acid fermentation spontaneously (Drosinos and Paramithiotis, 2007). Lactic acid fermentation of vegetables being traditionally a spontaneous and uncontrolled process results into undesirable and inconsistent products owing to the presence of diverse micro flora and various other variable factors. This has raised the necessity of adopting various strategies to control the lactic acid fermentation and the consequent product variability. The use of chemicals including sodium benzoate has been used widely to control the over-acidification of the fermented food product. However, the use of chemicals as such has not shown any significant results at the prescribed limits as evident from the literature. Microwave may be used to control the over-acidification of the food product by either slowdown or arrest the growth of microbes.

The main aim of the current study was therefore to control or slowdown fermentation of vegetables (cauliflower) after achieving a desired level of acidity so as to enhance the shelf life of the product and maintain its consumer acceptability during storage and marketing.

\section{MATERIALS AND METHODS}

\section{(a) Raw material}

Cauliflower was procured from local market and was brought to the Food processing pilot plant of the department of Food science and Technology. The vegetables which were free from physical damage, dirt, dust and other defects were used for the product formulation. 


\section{(b) Chemicals and reagents}

The chemicals and reagents used for Physico-chemical and microbial were purchased from Sigma-Aldrich Chemie (Buchs, Switzerland), Himedia India. All the chemicals were of analytical grade.

\section{(c) Product formulation}

The vegetables were thoroughly washed under tap water. Surface leaves of cauliflower were removed and florets were separated from the central stalk. The cauliflowers were peeled and tops were cut off. Washed cauliflowers were shredded into pieces (3-4 $\mathrm{cm}$ in length and $1 \mathrm{~cm}$ thick) and were weighed. The spices like ginger and garlic were peeled, chopped and then coarsely pounded. Mustard, red chilli and turmeric were used in powder form.

Table 1: Composition and quantity of spices used in the preparation of cauliflower pickle

\begin{tabular}{lll}
\hline S1. No. & Spice & Quantity $(\mathrm{g} / \mathbf{1 0 0 0 g})$ \\
\hline 01 & Red chilli powder & 12 \\
02 & Turmeric powder & 10 \\
03 & Mustard seeds & 35 \\
04 & Carom seeds & 35 \\
05 & Garlic & 30 \\
06 & Ginger & 30 \\
07 & Mustard oil & 140 \\
\hline
\end{tabular}

er, carom seeds were used in intact form. Shredded vegetables were dried under sunlight for 3 hours in order to remove the surface moisture with periodic turnings. The dried vegetables were mixed with specific quantity of spices and other ingredients (Table 1 ). $3 \%$ salt was added to the mixture on $\mathrm{w} / \mathrm{w}$ basis. The product so obtained was then filled in previously sterilized plastic containers. The filled containers were stored in the incubator (Memmert INE 500, Germany) at $21{ }^{\circ} \mathrm{C}$. The containers were monitored continuously until desirable acidity was achieved. The fermented products were divided into two portions. One portion of them was subjected to sodium benzoate treatment at concentrations of 350, 450 and 550 ppm while as the other was subjected to microwave treatment for $2.5,3.5$ and $4.5 \mathrm{~min}$. The treated products were then filled into glass bottles separately and was labeled as $S_{1}\left(350\right.$ ppm), $S_{2}(450$ ppm) $S_{3}(550 \mathrm{ppm}) \mathrm{M}_{1}(2.5 \mathrm{~min}), \mathrm{M}_{2}(3.5 \mathrm{~min})$ and $\mathrm{M}_{3}$ (4.5 min), respectively. One bottle kept untreated was used as control (C).

\section{(d) $\mathrm{pH}$ analysis}

The $\mathrm{pH}$ measurements of samples were carried out at regular intervals of time. Samples were homogenized (wise TIS homogenizer HG-15A, Korea) and left undisturbed for 20 minutes. The samples were centrifuged at $1200 \mathrm{rpm}$ for 20 minutes. The supernatant obtained was used for the analysis of $\mathrm{pH}$. The $\mathrm{pH}$ of the samples was determined by $\mathrm{pH}$ meter (HANNA-HI 2215 pH/ORP meter, Romania).

\section{(e) Titratable acidity (TA)}

Titratable acidity of the samples was determined by titrimetric method. Sample of 10 gm was homogenized (Wise TIS homogenizer HG-15A, Korea) with $100 \mathrm{ml}$ of distilled water. To the $10 \mathrm{ml}$ of aliquot, few drops (2-3) of phenolphthalein was added as an indicator. The acids (lactic acid) in the samples were titrated against $0.1 \mathrm{~N} \mathrm{NaOH}$ and expressed as mg lactic acid $100 \mathrm{gm}$ of fermented pickle extracts. The percentage of the lactic acid was calculated as follows:

$$
\text { Acidity } \%=\frac{\mathrm{N} \times \text { Eq.Wt. of acid } \times \text { Vol. made }}{\text { Wt. of sample } \times \text { Vol. of aliquot } \times 1000} \times 100
$$

\section{(f) Microbiological analysis}

Total plate count of each sample was done aseptically by transferring $1 \mathrm{~mL}$ of sample into $9 \mathrm{~mL}$ of sterile Peptone water buffered (Biolab, Merck, Germany). The contents were mixed thoroughly. MRS agar was used as nutrient media for the enumeration. Serial dilutions for each of the sample were done according to. All the glassware used during the microbial analysis was pre-sterilized. Plates were incubated at $37^{\circ} \mathrm{C}$ for 48 hours. The microbial load was expressed as $\log _{10} \mathrm{cfu} / \mathrm{g}$ for each sample. 
(g) Instrumental color

The color values of the fermented pickle samples during the storage period were determined using a Hunter Color Lab (Mini Scan XE Plus, model No. 45/0L, Hunter Associates Laboratory, Reston,VA). The instrument was calibrated with black and white tiles before color measurement. The " $L$ " value indicates the lightness, with 0-100 representing dark to light. The " $a$ " value gives the degree of the red-green color, with a higher positive " $a$ " value indicating more red. The " $b$ " value indicates the degree of the yellow-blue colour, with a higher positive " $b$ " value indicating more yellow. The average value of three replicates was calculated.

\section{(h) Texture analysis}

The textural analysis of the each sample was done by 5-blade Kramer share cell (HDP/KS5) using texture analyzer (Stable micro system, Model TA.XT plus, England). Texture profile analysis (TPA) was performed in duplicate on each sample at room temperature. Samples were taken from the center of each glass bottle. The conditions for texture analysis were as follows: test speed $3.00 \mathrm{~mm} / \mathrm{sec}$, post- test speed $10.00 \mathrm{~mm} / \mathrm{sec}$, maximum load $50 \mathrm{~kg}$, distance $25 \mathrm{~mm}$ and trigger type 'button'. Prior to analysis, the height of the blades was calibrated. The texture profile analysis was obtained by graphing a curve using force $(\mathrm{g})$ and time (sec) plots. A value of mean maximum force (firmness) was determined for each sample.

\section{(i) Sensory analysis}

The sensory analysis of the fermented product was done on the basis of 9- point hedonic scale for attributes like, flavour, sourness, firmness and color. Sensory analyses were carried out by the research scholars and faculty members ( 25 to 48 years of age) in the Department of Food Science and Technology. Samples were coded and served at room temperature with water. Samples were given to panelists separately for unbiased evaluation of sensory attributes. Taste was evaluated as sourness, texture as firmness, flavour intensity. However, overall acceptability was evaluated as the sum of all the sensory attributes considered and was calculated.

\section{(j) Statistical analyses}

The statistical analyses were performed using the IBM SPSS statistics 21. The differences among the treatments were evaluated statistically by one-way analysis of variance (ANOVA) and Duncan's multiple tests. All data were two sided at the $5 \%$ significance level and are reported as means \pm standard deviations (SDs).

\section{RESULTS AND DISCUSSION}

(a) Microbial stability

The values of the microbial count for the different samples are given in the Fig. 1.

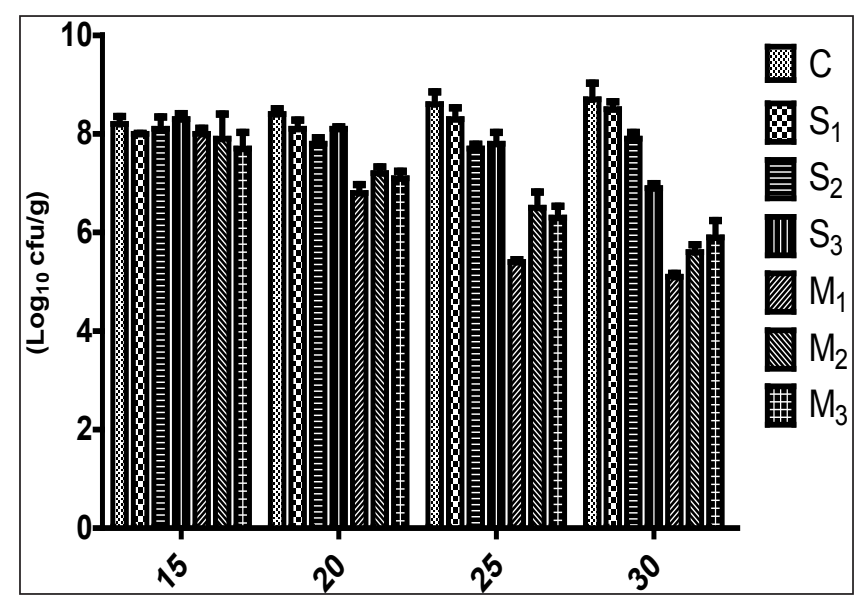

Fig. 1: Microbial load of different samples of cauliflower pickle

The microbial count in the control (C) was found to increase rapidly reaching to a value of $8.2 \log _{10}$ $\mathrm{cfu} / \mathrm{g}$ at the 15-day of fermentation and continued to increase to $8.7 \log _{10} \mathrm{cfu} / \mathrm{g}$ at 30-day of fermentation. Microbial count increased non-significantly in $S_{1}(8.0-$ $\left.8.5 \log _{10} \mathrm{cfu} / \mathrm{g}\right), \mathrm{S}_{2}\left(8.1-7.7 \log _{10} \mathrm{cfu} / \mathrm{g}\right)$ and $\mathrm{S}_{3}(8.3-6.9$ $\left.\log _{10} \mathrm{cfu} / \mathrm{g}\right)$ as compared to control indicating that sodium benzoate up to concentration of $550 \mathrm{ppm}$ does not show any inhibitory effect on LABs. These results are in accordance with the previous studies (Turantas et al. 1999). But in case of $M_{1}, M_{2}$ and $M_{3}$ there was a significant decrease in microbial count 
throughout storage study. The observations revealed that microwave treatment had a better control on microbial population as compared to sodium benzoate. These results are in agreement with the earlier study (Arenzana et al. 2012).

\section{(b) Sensory quality}

The overall acceptability of the samples are presented in the table 2. The score for $S_{1}, S_{2}$ and $S_{3}$ were $8.3,8.1$ and 8.6, respectively which decreased to 7.1, 6.9 and 6.4 respectively after 30 days of storage. The score of $\mathrm{M}_{1}, \mathrm{M}_{2}$ and $\mathrm{M}_{3}$ decreased from 8.5, 8.6 and 7.9 to 8.1, 6.8 and 7.5, respectively on the 30 day of storage. These results show that the overall acceptability of the $M_{1}$ received highest rating from the panelists. The sensory quality of the samples that were treated with sodium benzoate did not differ significantly from that of control. However the sample $\mathrm{M}_{2}$ received significantly lower scores from the panelists among the microwave treated samples. The samples $\mathrm{M}_{2}$ and $M_{3}$ received the lower scores due to the textural degradation by microwave heating. These results are in agreement with the earlier study (Turantas et al. 1999).

Table 2: Sensory quality (Overall acceptability) of fermented cauliflower at different storage periods

\begin{tabular}{lllll}
\hline Treatment & 15 day & 20 day & 25 day & 30 day \\
\hline $\mathrm{C}$ & $8.9 \pm 0.01^{\mathrm{a}}$ & $8.6 \pm 0.08^{\mathrm{d}}$ & $8.5 \pm 0.15^{\mathrm{g}}$ & $7.3 \pm 0.05^{\mathrm{b}}$ \\
$\mathrm{S}_{1}$ & $8.3 \pm 0.08^{\mathrm{f}}$ & $6.6 \pm 0.02^{\mathrm{b}}$ & $5.4 \pm 0.10^{\mathrm{d}}$ & $7.1 \pm 0.08 \mathrm{a}$ \\
$\mathrm{S}_{2}$ & $8.1 \pm 0.15^{\mathrm{d}}$ & $7.7 \pm 0.02^{\mathrm{f}}$ & $7.2 \pm 0.04^{\mathrm{f}}$ & $6.9 \pm 0.15^{\mathrm{a}}$ \\
$\mathrm{S}_{3}$ & $8.6 \pm 0.02^{\mathrm{b}}$ & $7.9 \pm 0.01^{\mathrm{c}}$ & $7.4 \pm 0.05^{\mathrm{b}}$ & $6.4 \pm 0.03 \mathrm{c}$ \\
$\mathrm{M}_{1}$ & $8.5 \pm 0.15^{\mathrm{g}}$ & $8.3 \pm 0.03^{\mathrm{g}}$ & $7.9 \pm 0.40^{\mathrm{e}}$ & $8.1 \pm 0.15^{\mathrm{d}}$ \\
$\mathrm{M}_{2}$ & $8.6 \pm 0.05^{\mathrm{b}}$ & $7.4 \pm 0.01^{\mathrm{c}}$ & $7.1 \pm 0.03^{\mathrm{g}}$ & $6.8 \pm 0.03 \mathrm{e}$ \\
$\mathrm{M}_{3}$ & $7.9 \pm 0.02^{\mathrm{c}}$ & $7.6 \pm 0.05^{\mathrm{f}}$ & $7.2 \pm 0.04^{\mathrm{c}}$ & $7.5 \pm 0.04^{\mathrm{f}}$ \\
\hline
\end{tabular}

Values are means $\pm S D$ and different letters indicates significant differences $(p<0.05)$ among samples by Duncan's multiple range test.

\section{(c) $\mathrm{pH}$ value}

The results obtained for $\mathrm{pH}$ value are given in the Fig. 2. The $\mathrm{pH}$ value of the raw sample was 6.5 and was found to apparently decrease in different samples during storage. Several other authors have also reported such a decreasing trend in the $\mathrm{pH}$ values of the pickles during storage (Khaskheli et al. 2015; Turantas et al. 1999; Spiros et al. 2020; Dhanapal et al. 1994). In case of control (C) the $\mathrm{pH}$ value decreased from 5.74 to 3.70 on 30-day of fermentation. The same trend in the decrease of $\mathrm{pH}$ value in the garlic pickle has been earlier reported (Raja and Mir 2016). Sample $\mathrm{M}_{1}$ showed decrease in the $\mathrm{pH}$ value from 5.62 at 15-day to 4.84 at the 30-day of fermentation. However the samples $\mathrm{S}_{1}, \mathrm{~S}_{2}$ and $\mathrm{S}_{3}$ did not showed any significant difference to that of control (C).

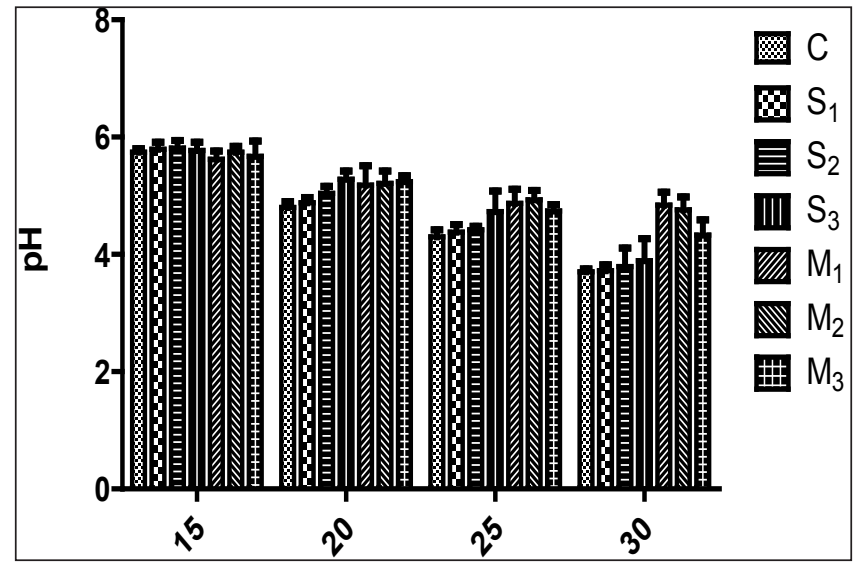

Fig. 2: $\mathrm{pH}$ of different samples of cauliflower pickle

\section{(d) Titratable Acidity}

The values of the titratable acidity obtained for the different samples are given in the table 3 . The value of acidity (as \% lactic acid) for the raw material was 0.27. The values of acidity for $S_{1}, S_{2}$ and $S_{3}$ were $0.90,0.91$ and 0.93 , respectively on the 15 -day of fermentation which increased to $1.45,1.43$ and $1.48 \%$, respectively at 30-day of storage, thus suggesting a significant increase in acidity. The samples $M_{1}, M_{2}$ and $M_{3}$ showed an decrease in the acidity values from 0.97 , 0.99 and 0.92 on the 15-day of fermentation to 0.96 , 0.97 and 0.86 respectively at 30-day of fermentation. Increase in acidity of $M_{1}, M_{2}$ and $M_{3}$ samples during storage might be due to release of $\mathrm{H}^{+}$and $\mathrm{NH}_{3}+$ from putrifecation. It is thus evident from the results that microwave treatment had a better control on acid production than sodium benzoate and the effect can 
be attributed to destruction of lactic acid bacteria by microwaves (Arenzana et al. 2012).

Table 3: Acidity (\% lactic acid) value of fermented cauliflower at different storage periods

\begin{tabular}{|c|c|c|c|c|}
\hline Treatment & 15 day & 20 day & 25 day & 30 day \\
\hline $\mathrm{C}$ & $0.89 \pm 0.03^{a}$ & $0.92 \pm 0.05^{\mathrm{d}}$ & $1.2 \pm 0.05^{\mathrm{g}}$ & $1.45 \pm 0.21^{b}$ \\
\hline$S_{1}$ & $0.90 \pm 0.08^{\mathrm{f}}$ & $0.96 \pm 0.02^{b}$ & $1.34 \pm 0.10^{\mathrm{d}}$ & $1.43 \pm 0.03^{a}$ \\
\hline$S_{2}$ & $0.91 \pm 0.05^{\mathrm{d}}$ & $0.95 \pm 0.05^{\mathrm{f}}$ & $1.37 \pm 0.14^{\mathrm{f}}$ & $1.48 \pm 0.13^{\mathrm{a}}$ \\
\hline $\mathrm{S}_{3}$ & $0.93 \pm 0.03^{b}$ & $0.96 \pm 0.11^{\mathrm{c}}$ & $0.99 \pm 0.15^{b}$ & $1.12 \pm 0.06 c$ \\
\hline $\mathrm{M}_{1}$ & $0.97 \pm 0.15^{g}$ & $1.07 \pm 0.13^{g}$ & $1.11 \pm 0.40^{\mathrm{e}}$ & $0.96 \pm 0.15^{\mathrm{d}}$ \\
\hline $\mathrm{M}_{2}$ & $0.99 \pm 0.05^{b}$ & $1.09 \pm 0.05^{c}$ & $1.04 \pm 0.03^{g}$ & $0.97 \pm 0.13^{\mathrm{e}}$ \\
\hline $\mathrm{M}_{3}$ & $0.92 \pm 0.10^{c}$ & $1.02 \pm 0.05^{\mathrm{f}}$ & $0.99 \pm 0.06^{c}$ & $0.86 \pm 0.04^{f}$ \\
\hline
\end{tabular}

\section{(e) Texture}

The firmness $(\mathrm{N})$ values obtained for control and samples treated with microwave and sodium benzoate are given in the table 4 . All samples showed decrease in the firmness during storage. Sample $S_{2}$ showed the highest decline (4.9) at 30-day of fermentation. For the sample $S_{1}, S_{2}$ and $S_{3}$ the firmness decreased from $6.8,6.9$ and 6.9 to 5.3, 4.9 and 5.1, respectively after 30 days of storage. Samples $M_{1}(6.6)$ and $M_{2}(6.3)$ also show a decrease in the firmness after 30 days of storage. Similar trend were observed in pickled vegetables due to thermal processing (Fleming et al. 1993; Papageorge et al. 2003).

Table 4: Firmness $(\mathrm{N})$ value of fermented cauliflower at different storage periods

\begin{tabular}{lllll}
\hline Treatment & 15 day & 20 day & 25 day & 30 day \\
\hline $\mathrm{C}$ & $6.8 \pm 0.03^{\mathrm{a}}$ & $6.7 \pm 0.05^{\mathrm{d}}$ & $6.3 \pm 0.05^{\mathrm{g}}$ & $6.1 \pm 0.21^{\mathrm{b}}$ \\
$\mathrm{S}_{1}$ & $6.8 \pm 0.08^{\mathrm{f}}$ & $6.6 \pm 0.02^{\mathrm{b}}$ & $5.4 \pm 0.10^{\mathrm{d}}$ & $5.3 \pm 0.03^{\mathrm{a}}$ \\
$\mathrm{S}_{2}$ & $6.9 \pm 0.05^{\mathrm{d}}$ & $6.7 \pm 0.05^{\mathrm{f}}$ & $5.3 \pm 0.14^{\mathrm{f}}$ & $4.9 \pm 0.13^{\mathrm{a}}$ \\
$\mathrm{S}_{3}$ & $6.9 \pm 0.03^{\mathrm{b}}$ & $6.4 \pm 0.11^{\mathrm{c}}$ & $6.3 \pm 0.15^{\mathrm{b}}$ & $5.1 \pm 0.06 \mathrm{c}$ \\
$\mathrm{M}_{1}$ & $7.0 \pm 0.15^{\mathrm{g}}$ & $6.8 \pm 0.13^{\mathrm{g}}$ & $6.7 \pm 0.40^{\mathrm{e}}$ & $6.6 \pm 0.15^{\mathrm{d}}$ \\
$\mathrm{M}_{2}$ & $7.0 \pm 0.05^{\mathrm{b}}$ & $7.1 \pm 0.05^{\mathrm{c}}$ & $6.7 \pm 0.03^{\mathrm{g}}$ & $6.3 \pm 0.13^{\mathrm{e}}$ \\
$\mathrm{M}_{3}$ & $6.9 \pm 0.10^{\mathrm{c}}$ & $6.7 \pm 0.05^{\mathrm{f}}$ & $6.5 \pm 0.06^{\mathrm{c}}$ & $6.2 \pm 0.04^{\mathrm{f}}$ \\
\hline
\end{tabular}

Values are means $\pm S D$ and different letters indicates significant differences ( $p<0.05)$ among samples by Duncan's multiple range test.

Print ISSN: 2319-3549

\section{(f) Color}

The values obtained for the instrumental color of the samples during storage study are given in the table (5). The "L" value showed a constant decrease in the control sample (38.97 to 36.38) during the storage. However " $L$ " value increased in the $S_{1}$ (39.32 to 41.22), $S_{2}(39.86$ to 43.11$)$ and $S_{3}(42.41$ to 43.26$)$ samples. The "a" value increased continuously among all treated samples including control sample from day 0 up to day 30 of the fermentation. The " $b$ " value showed increasing trend in all samples including control. Similar trend in instrumental color was observed in carambola pickle (Igrid and Neela, 2004).

Table 5: Color value of fermented cauliflower at different storage periods

\begin{tabular}{|c|c|c|c|c|c|}
\hline Sample & Attributes & 15 days & 20 days & 25 days & 30 days \\
\hline \multirow{3}{*}{ Control } & $L$ & 38.97 & 38.10 & 37.41 & 36.38 \\
\hline & $a$ & -1.43 & -1.22 & 1.43 & 1.63 \\
\hline & $b$ & 8.76 & 8.93 & 10.33 & 11.30 \\
\hline \multirow{3}{*}{$\mathrm{S}_{1}$} & $L$ & 39.32 & 39.94 & 40.31 & 41.22 \\
\hline & $a$ & -1.49 & -1.58 & 1.43 & 1.98 \\
\hline & $b$ & 8.81 & 8.99 & 10.91 & 11.21 \\
\hline \multirow{3}{*}{$S_{2}$} & $L$ & 39.86 & 39.98 & 41.12 & 43.11 \\
\hline & $a$ & -1.57 & -1.63 & 1.73 & 2.14 \\
\hline & $b$ & 8.93 & 9.31 & 11.32 & 11.49 \\
\hline \multirow{3}{*}{$\mathrm{S}_{3}$} & $L$ & 42.41 & 40.06 & 41.68 & 43.26 \\
\hline & $a$ & -2.62 & -2.86 & 2.01 & 2.32 \\
\hline & $b$ & 8.97 & 9.42 & 11.43 & 11.63 \\
\hline \multirow{3}{*}{$\mathrm{M}_{1}$} & $L$ & 46.23 & 42.23 & 42.99 & 44.18 \\
\hline & $a$ & -2.82 & -2.91 & 2.22 & 2.68 \\
\hline & $b$ & 9.01 & 9.44 & 11.96 & 12.21 \\
\hline \multirow{3}{*}{$\mathrm{M}_{2}$} & $L$ & 52.31 & 42.46 & 43.68 & 44.88 \\
\hline & $a$ & -2.96 & -3.02 & 3.15 & 3.43 \\
\hline & $b$ & 9.32 & 9.56 & 12.01 & 12.53 \\
\hline \multirow{3}{*}{$\mathrm{M}_{3}$} & $L$ & 58.68 & 42.66 & 43.81 & 44.96 \\
\hline & $a$ & -3.01 & -3.33 & 3.43 & 3.53 \\
\hline & $b$ & 9.38 & 9.63 & 12.22 & 12.43 \\
\hline
\end{tabular}

\section{CONCLUSION}

This study demonstrated the applicability of microwave treatment as an effective method to arrest/ slowdown the bacterial growth during fermentation. 
While as application of sodium benzoate did not show any significant inhibitory effect on bacteria's particularly LABs at concentration of up to 550 ppm. However minimal texture degradation due to microwave heating needs to be overcome. Pretreatments must be applied to improve the textural properties of the pickle. Also the microwave exposure for longer time had slight negative influence on the sensory attributes of the pickle. Therefore a proper technological intervention is needed to enhance the overall quality parameters of the fermented Cauliflower pickle.

\section{ACKNOWLEDGEMENTS}

This work was done at Department of Food Science and Technology, University of Kashmir. The authors are highly thankful to the Department of Biotechnology, Ministry of Science and Technology (IN), Govt. of India for financial assistance. The facilities and services provided by the Department are gratefully acknowledged.

\section{REFERENCES}

Adams, M. and Mitchell, R. 2002. Fermentation and pathogen control: a risk assessment approach. Int. J. Food Microbiol., 79: 75-83.

Adams, M.R. and Nout, M.J.R. 2001. Fermentation and food safety. Gaithersburg, Md: Aspen publishers, Inc. eds.

Arenzana, L.G., Santamaria, P., Lopez, R., Garijo, P., Gutierrez, A.R., Cerdan, T.G. and Alfaro, I.L. 2012. Microwave technology as a new tool to improve microbiological control of oak barrels: A preliminary study. Food Cont., 30: 536-539.

Block, G., Patterson, B. and Subar, A. 1992. Fruits, vegetables and cancer prevention: A review of the epidemiological evidence. Nutr. Cancer, 18: 1-29.

Cordell, G.A., Telma, L.G.L., Francisco, J.Q.M. and Marcos, C. 2007. Vegetables as chemical reagents. J. Natu. Prod., 70: 478-92.

Dhanapal, K., Ratnakumar, K. and Jasmine, T.G. 1994. Processing chank meat (Xancus pyrum) into pickles. Fish Technol., 31: 188-190.

Dominique, B., Sylvie, L., Simon, L.D., Jessica, J., Edith, B., Martine, C., Albert, M., Stephane, B. and Denis, G. 2009. Antiproliferative and antioxidant activities of common vegetables. J. Food Chem., 112: 374-380.
Drosinos, E.H. and Paramithiotis, S. 2007. Research trends in lactic acid fermentation. In M.V. Palino (Ed.), Food microbial. res. trends, Nova Science publishers, pp. 39-92.

Fleming, H.P., Thompson, R.L. and McFeeters, R.F. 1993. Firmness retention in pickled peppers as affected by calcium chloride, acetic acid and pasteurization. J. Food Sci., 58: 325-330.

Hertog, M.G.L., Kromhout, D., Aravanis, C., Blackburn, H., Buzina, R. and Fidanza, F. 1995. Flavonoid intake and long term risk of coronary heart disease and cancer in the seven countries study. Archives Int. Med., 155: 381-386.

Igrid, M.F. and Neela, B. 2004. Effects of brining pretreatment and storage on carambola (Averrhoa Carambola L.) pickle. J. Food Proc. Preser., 28: 51-67.

International Commission on Microbiological Specifications for Foods. 1996. Microorganisms in foods: Characteristics of microbial pathogens. Springer Science and Business Media, London, UK, pp. 45-328.

Khaskheli, S.G., Zheng, Sheikh, S.A., Khaskheli, A.A., Liu, Wang, Y.F. and Huang, W. 2015. Effect of processing techniques on the quality and acceptability of Auricularia auricular Mushroom pickle. J. of Food and Nutr., 3: 46-51.

Li, K.Y. 2004. Fermentation: principles and microorganisms. In: Hui, Y.H., Meunier-Goddik L., Hansen A.S, Josephsen J., Nip W.K., Stanfield P.S, Toldra F. (eds.), Handbook of Food and Beverage Fermentation Technology, Newyork: Marcel Dekker, pp. 595-609.

Papageorge, L.M., McFeeters, R.F. and Fleming, H.P. 2003. Factors influencing texture retention of salt free, acidified, red bell peppers during storage. J. Agri. Food Chem., 51: 1460-1463.

Prajapati, J.B. and Nair, B.M. 2003. The history of fermented foods. In: Farnworth, E.R. (Ed.) Fermented Functional Foods. CRC Press, Boca Raton, New York, London, Washington DC, pp. 1-25.

Raja, J., Mir, S.A. and Masoodi, F.A. 2016. Effect of Dry Salt and Brine on the Fermentation and Colour of Blanched Garlic. J. Nutr. Food Sci., 6: 484.

Rao, P.S. 1995. Iodine deficiency disorders-goitrogens and brain development. Nut. News, 16: 1-3.

Shivapriya, M., Kotamballi, N.C.M. and Bhimanagouda, S.P. 2012. Crucial facts about health benefits of popular cruciferous Vegetables. J. Funct. Foods, 4: 94-106.

Sicard, D. and Legras, J.L. 2011. Bread, beer and wine: yeast domestication in the Saccharomyces sensu strict complex. Comptes. Rendus. Biologies, 334: 229-236.

Spiros, P., Olga, L.H., Eleftherios, H. and Drosinos, E. 2010. Development of microbial community during cauliflower fermentation. Int. J. Food Res., 43: 1098-1103.

Turantas, F., Goksungur, Y., Dincer, A.H., Unluturk, A., Guvenc, U. and Zorlu, N. 1999. Effect of potassium 
sorbate and sodium benzoate on microbial population and fermentation of black olives. J. Food Sci. Agr., 79: 1197-1202. USDA, National Nutrient Database. 2009.

Van Boekel, M., Fogliano, V., Pellegrini, N., Stanton, C., Scholz, G., Lalljie, S., Somoza, V., Knorr, D., Jasti, P.R. and Eisenbrand, G. 2010. A review on the beneficial aspects of food processing. Molecular Nutr. Food Res., 54: 1215-1247.
Vasanthi, H.R., Mukherjee, S. and Dipak, K. 2009. Potential health benefits of broccoli. J. Food Microbiol., 95: 147-55.

Wettasinghe, M., Bolling, B., Plhak, L. and Parkin, K. 2002. Screening for phase enzyme- inducing and antioxidant activities of common vegetables. J. Food Sci., 67: 2583-88. 